\title{
NEW ZEALAND RESEARCH
}

\section{Survey results of first and second year New Zealand midwifery students' level of engagement in a flexible delivery programme}

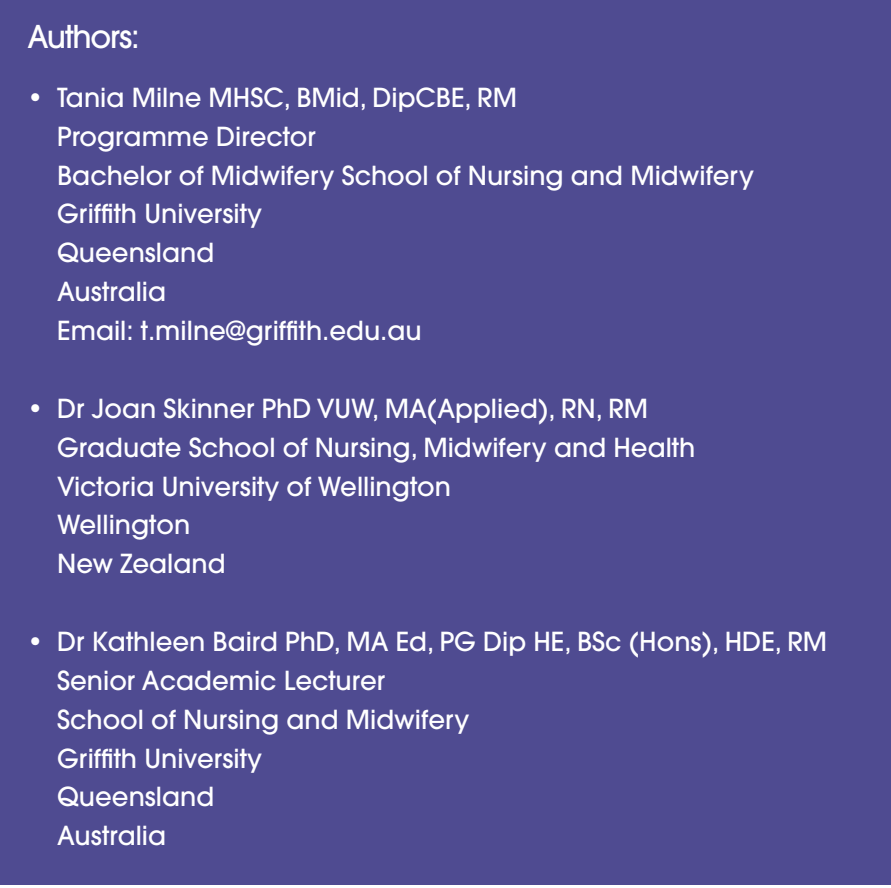

\section{ABSTRACT}

Objective: This paper describes the survey results of first and second year New Zealand (NZ) midwifery students' level of engagement while being taught in face-to-face, videoconference (VC) and online activities as part of a fully flexible delivery curriculum.

Methods: First and second year undergraduate midwifery students ( $\mathrm{n}=$ 104) from one New Zealand midwifery education provider were invited to participate and complete an online survey. Students were recruited from the main city campus learning hub and three smaller regional learning hubs (RLH).

Measurements: The survey asked for: demographic information, skills, experience and confidence with modes of flexible learning, information technology, online student learning platforms, and engagement with learning. Data were analysed using descriptive statistics including minimum and maximum scores, means, ranges and weighted averages.

Results: $52 \%(\mathrm{n}=54)$ of students provided feedback. $40 \%(\mathrm{n}=21)$ of respondents considered they had minimal experience with online learning platforms and $48 \%(\mathrm{n}=49)$ indicated a lack of confidence to participate in learning sessions delivered via VC. $66 \%(n=67)$ of respondents rated their involvement in learning much higher in face-to- face sessions than with VC. Respondents felt more engaged with their peers from their own regional learning hub (RLH) and less with the teaching, clinical and administration teams.

Conclusion: Students need to be orientated and educated to use technology adequately for their learning. Although flexible modes of delivery in midwifery education enhance student access, the quality of learning requires reliable technology with good capacity, and pedagogy that fosters a high level of interaction. Rural and remote students rated engagement with face-to-face teaching highly. Support and continuing training and education for both faculty and students need to be offered to maximise the potential of flexible delivery modes. This was a small survey with students from one NZ midwifery education provider. Results need to be interpreted with this in mind.

\section{KEY WORDS}

Midwifery education, students, distance learning, flexible delivery, e-technology, e-learning

\section{INTRODUCTION}

There is growing interest in the advantages and disadvantages of distance education, flexible delivery, e-technology and student engagement (Australian Council for Educational Research, 2010; Greenberg, 2004; Ministry of Education, 2002; Normand \& Littlejohn, 2006; Ramage, 2002; U.S. Department of Education, 2009). Engaged adult learners are more likely to be academically challenged, active in their learning, interact with faculty, have an enriched learning experience and be more able to integrate their learning and work experiences (Winnie, 2010).

E-learning offers and potentially enables a more collaborative approach to midwifery students' learning and future practice. According to Clarke (2009), web-based technologies in health care have led to the establishment of new partnerships between midwives and other health practitioners, as well as with the women accessing services. More maternity consumers are now actively participating in e-technology for their own research about childbirth (Clarke, 2009). Developing midwifery students' technological skills, may foster their ability to actively participate 'with women' on an e-level in the future (Clarke, 2009).

Student engagement can be enhanced through robust flexible delivery of teaching (Australian Council for Educational Research, 2010). The successful provision of a blended curriculum, of which e-learning is a component, requires appropriate support and development of teacher and student skills. Both students and faculty can struggle in the transition to learning and teaching using different modes of delivery (O’Neill, Singh \& O’ Donoghue, 2004). Previous research has 
predominantly examined the impact of flexible delivery in postgraduate programmes or single courses within undergraduate programmes. There has been relatively little evaluation on the impact of a fully flexible midwifery undergraduate programme. This paper describes undergraduate midwifery students' level of engagement in a flexible delivery programme.

\section{MIDWIFERY EDUCATION IN NEW ZEALAND}

The historical path of midwifery education in New Zealand, like many other Commonwealth countries, has been one of cyclic change. The first endeavour to regulate midwifery education in 1904 aimed to provide a framework and increase the safety of maternity services (Pairman \& Donnellan-Fernandez, 2010). Over the last two decades midwifery education shifted from apprentice-style hospital based learning, to education within technical institutes and universities. Between 1904 and the mid1950s midwifery training took place in one of seven maternity hospitals known as St Helens Hospitals. Other state owned hospitals offered a mix of training options including direct entry midwifery, and additional midwifery training following nursing training. In 1956 direct entry midwifery education was slowly phased out with midwifery integrated into general nursing and maternity nurse training. Increasing pressure from NZ Nurses Organisation to replace the midwife with a nurse who had a post registration and maternity nursing specialty resulted in a short lived course for would-be midwives - one year's study in a polytechnic alongside other nurses seeking other speciality nursing qualifications. This effectively radically reduced the number of those pursuing a midwifery qualification within their own country. However, the dire threat to the profession politicised both midwives and consumers (Pairman, 2005; Stojanovic, 2010). There was little change to midwifery education over the next 20 years until the 1980s. Strong maternity consumer pressure from groups such as the Home Birth Association and Parents Centre together with determined political lobbying by NZ midwives via the Midwives and Maternity Nurses' Special interest Groups of NZ Nurses Organisation saw legislative change which led to the passing of the Nurses Amendment Act 1990, midwifery autonomy of practice and separate midwifery education programs (Pairman $\&$ Donnellan-Fernandez, 2010, Stojanovic, 2010).

Having been subsumed as a post registration qualification of nursing for many years, midwifery in New Zealand became a stand-alone profession. In 1992, two direct entry midwifery pilot programmes commenced. After extensive review of these programmes, a further three institutes gained approval (Pairman, 2006). Now in New Zealand midwifery education is only offered as a direct entry undergraduate four year (equivalent) degree. The profession is regulated by the Midwifery Council of New Zealand (MCNZ) (MCNZ, 2007) and has a professional college, the New Zealand College of Midwives (NZCOM) (Guilliland \& Pairman, 2010).

The current midwifery programme accreditation standards in New Zealand have a strong focus on student centred learning and partnership between teachers and learners (MCNZ, 2007). This approach reflects the New Zealand midwifery philosophy that commits to partnership with women, women centred care, and autonomous practice (Guilliland \& Pairman, 2010). Development of midwifery curricula saw a shift to more flexible modes of delivery. This was evidenced by moves from the traditional classroom style of teaching to more distributed styles of learning. Many midwifery students in New Zealand attend some teaching sessions by distance learning (MCNZ, 2007, Ministry of Education 2010).

This impetus for change in midwifery education delivery was legislative and industry driven to address a number of issues such as midwifery workforce shortages especially in remote rural areas, and a projected shortfall of midwives due to the aging midwifery workforce. Flexible

\section{Development of a well-} supported flexible delivery BMid programme would be accessible to a diverse cohort of midwifery students, and minimise the need for students and their families to relocate for
their study.

delivery of programmes also had the potential to enable and encourage more Māori into midwifery, and support different teaching and learning formats to meet individual students' learning styles (Health Workforce New Zealand, 2008; MCNZ, 2010; Ministry of Education, 2010).

In New Zealand, four metropolitan institutions (two in each of the North and South Islands) are accredited by the MCNZ to offer a Bachelor of Midwifery (BMid). Development of a well-supported flexible delivery BMid programme would be accessible to a diverse cohort of midwifery students, and minimise the need for students and their families to relocate for their study. The midwifery education provider, where the survey was held, addressed this issue by offering students the opportunity to stay in their home towns, attend lectures by videoconference (VC), to participate in online activities, and gain clinical experience in their area.

\section{CONTEXT FOR THIS STUDY}

In 2010, after gaining MCNZ accreditation, the midwifery department where this research was conducted, began teaching a new undergraduate midwifery curriculum to 75 first year students. Continuing students in Years Two and Three completed the previous curriculum. The new midwifery program was offered by flexible delivery. This included a blend of methods, face-to-face, video conferencing (VC) and online learning. The flexible delivery of the curriculum aimed to address the national issues of rural recruitment, retention of the midwifery workforce and open access to midwifery education (Health Workforce NZ, 2008; MCNZ, 2010; Ministry of Education, 2010).

Around $30 \%$ of students were located in rural/remote areas and participated by distance learning. To support this distributed student cohort, four learning hubs were established: the central and host site for videoconferencing based at the main city campus (MCH); and three other sites established at regional polytechnics and called regional learning hubs (RLHs). The MCNZ required students to attend one third of their academic teaching at the main campus, to enable face-to-face teaching, clinical skills learning and tutorials with their student cohort (School of Nursing and Midwifery, 2009). The remaining teaching sessions were delivered by videoconference or online learning. Students 
at the host site continued to experience face-to-face teaching in a classroom, in real time with the lecturer present. The teaching session was simultaneously video conferenced to distributed students attending the RLHs. Tutorial sessions were also online for distributed students and face-to-face for students on the main campus. The midwifery curriculum was the first flexibly delivered curriculum at this institute.

After the first year of offering the programme, faculty expressed concerns about VC. Initially, there were technical failures, inadequate technology support at the RLHs, and a higher than expected attrition especially from one regional area with more Māori students. Faculty reported that students with less face-to-face contact seemed less engaged and this may have contributed to student attrition.

Success in the use of flexible modes of delivery requires an adherence to very specific instructional and design ideologies, as well as a lot of luck (Carter \& Heale, 2010). For example, difficulties using videoconferencing, especially system capabilities and poor sound and picture quality, are commonly reported (Carter \& Heale, 2010). However, flexible delivery modes can also be hindered by the limited capabilities of educators. Professional development and ongoing e-technology upskilling of educators are imperative (Carter \& Heale, 2010). Successful flexible delivery requires organisational commitment, good technological management and resources, skilled faculty, and thorough pedagogical planning by faculty.

Videoconferencing can be a highly effective method of instruction if used in a truly interactive and collaborative style, but is not ideal or effective for lecture style teaching of large numbers or for lengthy sessions (Greenberg, 2004). Using VC effectively requires faculty to adapt content and their teaching approach to a highly interactive pedagogical situation (Greenberg, 2004). In the current context, faculty were also concerned that writing and planning effective online lesson plans took a considerable amount of time, and this was compounded by the roll-out of the new curriculum, so both method of teaching and content were new.

The main purpose of the current research was to gain an understanding of the impact of flexible delivery on student engagement. Specifically, the study sought to gauge midwifery students' skills and knowledge of e-learning technology, their experience of flexible delivery, and their engagement with learning activities, their peers and faculty.

\section{RESEARCH DESIGN}

The research approach was descriptive. A survey was developed and adopted the style and structure of the Australasian Survey of Student
Engagement (AUSSE) (Australian Council for Educational Research, 2010). The AUSSE tool has been used to survey over 450,000 Bachelor degree students across Australia and New Zealand (Australian Council for Educational Research, 2010). The tool focuses on student learning and outcomes and was therefore considered valid for use in the current study. The student engagement questionaire in AUSSE measures one hundred different aspects of engagement which apply to six engagement themes. Three of these themes were applied to the BMid survey: active learning, student and staff interaction, and supportive learning environment.

Other sections of the survey also used a Likert response scale under thematic questions and asked students about their demographic characteristics, place of learning, and the nature of their learning experiences. For example, question 13:

Question 13: Prior to entry into the BMid programme how would you rate
your skills with the following types of flexible delivery/learning? Give yourself a
rating between 1 -10
(1 being minimal, 5 moderate and 10 advanced)
Moodle
Videoconference
On-line learning
activities
On-line forums

This section of the survey aimed to provide some insight into the level of student engagement and sense of belonging with the BMid programme.

\section{PARTICIPANTS AND RECRUITMENT}

All 104 enrolled midwifery students in Year 1 and 2 of the [new curriculum] BMid pre-registration programme from one New Zealand midwifery education provider were invited to participate. A link to the survey website was sent via the institution's student email system and to the student Meta communication website, providing details of the URL link and password required to activate the survey. This was a global populated email list of all enrolled students.

\section{DATA COLLECTION AND ANALYSIS}

Data from the survey were collected via the Victoria University of Wellington, NZ, Qualtrics system. Each response was de-identified by an independent survey administrator and coded with a response number to protect the anonymity of all respondents.

Data from this survey were described by using the following formats: minimum and maximum scores, averages, ranges, weighted averages and the mean. Owing to the small sample and scope of the research project, inferential statistical analysis was not undertaken. Similar to analysis of the AUSSE tool, numbers and percentages were analysed including weighted and un-weighted numbers and percentages. Tables and graphs were used to demonstrate the gathered information.

\section{ETHICS}

Ethical approval was provided by both the Victoria University of Wellington's Human Research Ethics Committee, (Faculty of Humanities and Social Sciences) and the local ethics committee of the research department. Consent from participants was implied by completion of questionnaires, which were anonymous. Access to the research data was restricted to the research investigator and their 
supervisor. Some respondents were known to the researcher therefore consideration was given to the collection of demographic data; for example, gender was omitted from the data collection as there was only one male in the programme. Participants were not asked to provide their name and contact details. The raw data were collated by the survey web programme Qualtrics and had no identifying features; respondents were assigned a number based on the timing of their participation.

\section{RESULTS}

54 completed surveys were received from students in Year 1 and 2 of the new BMid programme giving a $52 \%$ response rate. The majority of respondents $(71 \%, \mathrm{n}=37)$ attended the $\mathrm{MCH}$ and $29 \%(\mathrm{n}=15)$ were from the RLHs.

\section{SKILL WITH FLEXIBLE LEARNING}

Participants were asked to rate their ability and confidence with different modes of flexible delivery of learning prior to entry into the programme and at the time of survey completion. Given the number of students who stated they had post-secondary school qualifications, it was surprising that $40 \%(\mathrm{n}=21)$ considered they had minimal experience with both the online learning platform called Modular Object-Oriented Dynamic Learning Environment (MOODLE), and VC. Nearly half of respondents $(48 \%, \mathrm{n}=25)$ stated having minimal skill with VC. When respondents were asked the same question regarding their skill with these modes of flexible learning at the present point in the programme, only one student reported having minimal skills with Moodle and $13 \%(\mathrm{n}=7)$ with VC (Figure 1).

Respondents were also asked to rate their confidence to participate in class with different modes of flexible delivery of learning. The majority of respondents $(88 \%, \mathrm{n}=85)$ strongly agreed or agreed with being confident to participate in online learning activities. However, when respondents were asked about their confidence to participate during the VC sessions, only $11.5 \%(n=6)$ strongly agreed they were confident to participate. Nearly half the cohort $(48 \%, \mathrm{n}=25)$ indicated a lack of confidence to participate in learning sessions when delivered via VC.

\section{LEARNING EXPERIENCES}

$66 \%(n=67)$ of respondents rated their involvement in learning much higher in face-to-face sessions than with VC (Figure 2). The mean response score for involvement in learning from face-to-face sessions was 7.22 out of a possible 10 , with a standard deviation of 1.84 . The mean score for involvement in learning during VC was 5.02 with a standard deviation of $2.11 .71 \%(n=37)$ of respondents stated their involvement was towards the maximum level of involvement (scoring seven through to 10$)$ when in face-to-face sessions compared to $25 \%(\mathrm{n}=13)$ in VC sessions. $6 \%(\mathrm{n}=3)$ rated their involvement level as below moderate to none in the face-to-face sessions compared with $38 \%(\mathrm{n}=20)$ rating their involvement below moderate for VC sessions.

When comparing the experiences of students enrolled at RLH to those attending at the MCH with face-to-face learning sessions, it was discovered that respondents from the RLHs indicated a higher level of involvement, learning and participation than their $\mathrm{MCH}$ counterparts. All RLH respondents $(100 \%, \mathrm{n}=29)$ indicated maximum learning from face-to-face sessions compared with $81 \%(n=30)$ of respondents from the $\mathrm{MCH}$. The results suggest that RLH respondents make the most of their learning experiences with face-to-face sessions when they attend block courses (intensives) at the $\mathrm{MCH}$.

\section{ENGAGEMENT}

Most respondents rated their engagement in learning much higher for face-to-face sessions compared to VC. With $71 \%(n=37)$ of respondents scoring seven through to 10 for engagement in face-to-

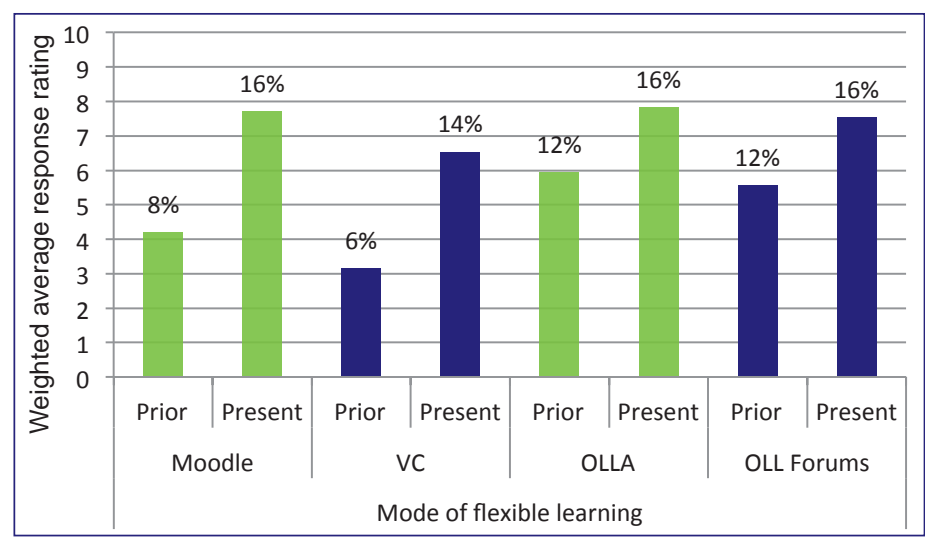

Figure 1: Weighted averages of participant responses to Skills with Modes of Flexible learning (Online Learning Activities (OLLA) Online Learning Forums (OLL Forums) prior to entry into BMid and at time of survey participation

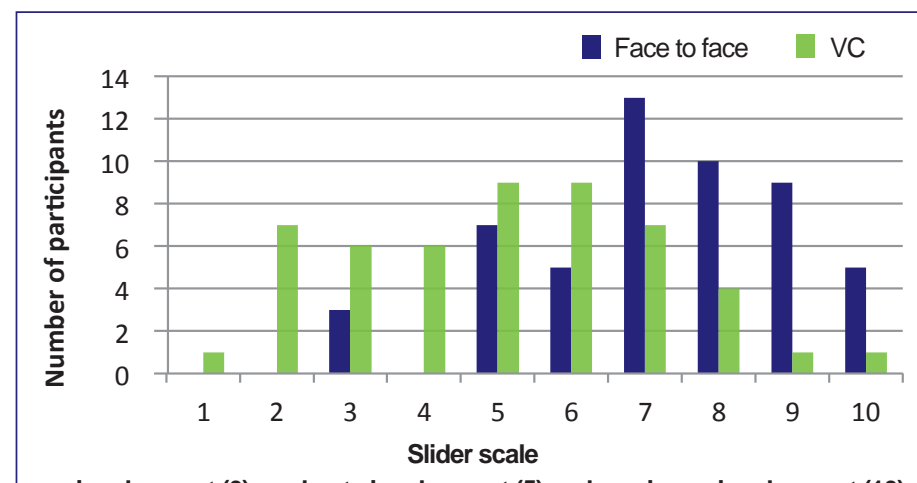

no involvement (0) moderate involvement (5) and maximum involvement (10)

Figure 2: Comparing level of involvement between face-to-face and videoconferencing

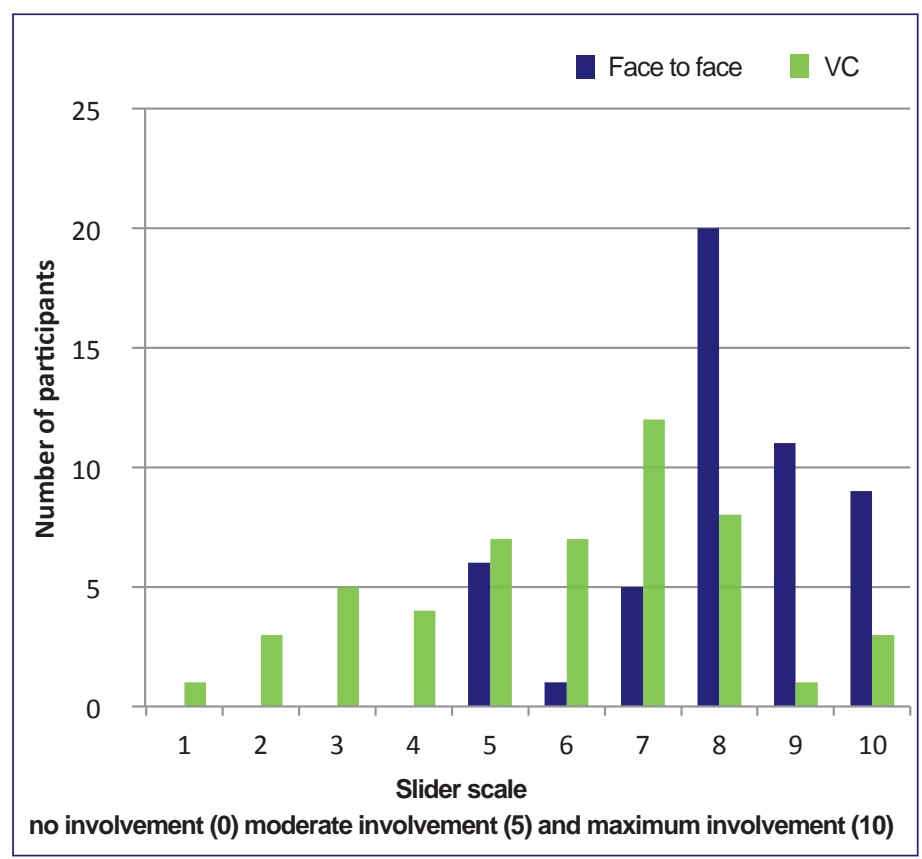

Figure 3: Respondents' perceived level of learning from tutors, comparing face-to-face and videoconference sessions 


\section{While challenges to learning for students were identified, they commented positively on the advantages of staying in their home towns for study.}

face-to-face classroom setting. Nevertheless the key component for successful learning is being interactive. Twice as many respondents stated they had maximum involement with sessions when face-to-face compared with VC sessions. Students reported being more engaged and felt confident to ask questions and participate in discussions during face-to-face interactions compared with VC sessions. This supports Greenberg's (2004) suggestion that a number of instructional strategies and support for faculty must be considered to create interactive VC sessions. There is a need for ongoing development of instructional strategies for maximising VC based learning sessions at the institutional level and for faculty (Carroll, Booth, Papaioannou, Sutton, \& Wong, 2009; USA Department of Education, 2009).

It was hypothesised that students from the RLHs would be less engaged and find VC more challenging than those attending the MCH. Students located in rural and remote areas clearly reported their appreciation of face-to-face sessions when attending the main campus every trimester. Most respondents from the RLH rated their involvement with face-toface sessions at a maximum level, compared with $\mathrm{MCH}$ respondents. Few reported high engagement with $\mathrm{VC}$ activities.

Many educational experts agree that instructional design has considerable influence on a students' ability to engage or succeed rather than mode of delivery (Carter \& Heale, 2010; Chickering \& Gamson, 1987; Greenberg, 2004; Kirpatrick, 2001; Kuh, Kinzie, Schuh, \& Whitt, 2005). Clearly, courses and programmes must be creative and effectual to meet the needs of different learners and learning styles. With time, it is anticipated that e-learning infrastructure will improve and faculty will be able to use technology to greater effect.

With the ongoing rapid growth in e-technologies for learning, faculty need to be supported to enhance their own learning. Institutions need to develop strategies that support the transition of faculty to delivery of flexible modes of learning. Boettcher (2011) suggests "just as learners are very individual, so too are faculty, therefore course designs need to be flexible so that faculty can shape designs to their skills and capabilities within a range of program requirements" (p. 11-12).

\section{LIMITATIONS}

This small descriptive study was undertaken at one multi-campus university in New Zealand. The experiences of this cohort of students may differ from other midwifery students learning in different contexts and cultures. The study achieved only a $52 \%$ (54 out of 104) response rate. It could be that students who did not participate were less engaged in the programme. But also the results of the study may, therefore, be an under-estimation of students' perceptions of flexible delivery modes.

The challenges of unreliable technology seemed to develop from inadequate support from the technical support teams and lack of preparation of faculty, especially those at the RLHs. Furthermore, some of the equipment was not appropriate for the demands required when using VC interactively. Neither staff nor students had been given the opportunity to develop their skills and practise learning and teaching 'via the screen'.

The original sessions for the BMid programme were timetabled for a more traditional style of teaching with a mix of face-to-face lectures and smaller tutorial type sessions that could be either face-to-face or via an online platform. However, with the change in mode of delivery to large blocks of VC sessions, there was little time for the teaching team to make adaptations to lessons such as incorporating either interactivity or the collaborative style that is specifically recommended for VC sessions (Clarke, 2009).

This research sought to assess student enagement with different modes of learning and teaching. While challenges to learning for students were identified, they commented positively on the advantages of staying in their home towns for study. Certainly, Greenberg (2004) noted that VC as means of delivery of teaching, can be just as effective as the traditional

Students reported being more engaged and felt confident to ask questions and participate in discussions during face to face interactions. 
Although a standardised tool was adapted for the survey, it could be that the items did not adequately measure key issues. Given the descriptive nature of the study, the inclusion of a qualitative component may have provided a richer insight into students' experiences. Future research should also attempt to engage students who have exited a programme. These students are likely to be more disaffected than students who continue, and valuable information could be gained from their feedback enabling the BMid teaching team to develop support strategies to better meet the needs of future indigenous and remote students.

Further research could compare the learning experiences of students across other BMid programs in New Zealand using different forms of flexible delivery. Additional development of the survey that incorporates more of the tested engagement scales from the AUSSE tool would be valuable to midwifery education. A qualitative research approach, particularly with Māori learners, would be valuable as there is a need to consider whether Māori students are more at ease with, and would consider small interactive face-to-face contact more culturally appropriate, as opposed to the predominance of e-technology.

Giving a voice to the midwifery faculty, acknowledging their experiences of flexible delivery of learning, would also help to identify any further gaps in the capacity of faculty to work within the context of e-learning. Having such data will lead to a clearer and better-integrated pedagogical framework for BMid programmes in New Zealand.

\section{CONCLUSION}

This paper described findings from a survey, which explored the impact of flexible delivery of teaching on first and second year midwifery students' ability to engage in a BMid programme. Findings support some earlier research that student's value teaching that is interactive and synchronous. Students and faculty need access to, and support for, ongoing training and education with the many modes of e-learning.

The New Zealand Government's Tertiary Strategy endorses teaching and learning that provide a learner-centred approach. This approach supports a vision, which will "reflect New Zealand's unique cultures and the special strengths of its teacher and educators" (Ministry of Education, 2002, p. 21). In a flexible learning environment that is student-centred, students' learning needs guide the process. This was a small survey with students from one NZ midwifery education provider. Results need to be interpreted with this in mind.

\section{REFERENCES}

Australian Council for Educational Research. (2010). Doing more for learning: enhancing engagement and outcomes. ACER. Victoria, Australia: Australian Council for Educational Research Ltd.

Boettcher, J. (2011). Designing online courses: models for improvement. Retrieved from : http://www.facultyfocus.com/newsletters/distance-education-report/. Faculty Focus.

Carroll, C., Booth, A., Papaioannou, D., Sutton, A., \& Wong, R. (2009). UK healthcare professionals' expereince of on-line learning techniques: a systemic review of qualitative data. Journal of Continuing Education in the Health Professions, 29(4), 235-241.

Carter, L. M., \& Heale, R. (2010). Teaching undergraduate nursing courses via videoconference: All that glitters is not gold. Journal of Distance Education (Online), 24(2), 109.

Chickering, A., \& Gamson, Z. (1987). Seven principles for good practice in undergraduate education. American Association for Higher Education, 39, 3-6.

Clarke, E. (2009). Introduction of e-learning into the pre-registration midwifery curriculum. British Journal of Midwifery 17(7), 432-437.

Greenberg, A. (2004). Navigating the sea of research on video conferencing-based distance education. Duxbury, USA: Wainhouse Research.
Guilliand, K., \& Pairman, S. (2010). The midwifery partnership: a model for practice (2nd ed.). Christchurch, NZ: New Zealand College of Midwives.

Health Workforce New Zealand, (2008). Workforce forecast: Midwives. Author, Wellington, NZ.

Kirkpatrick, D. (2001). Staff development for flexible learning. The International Journal of Academic Developent, 6(2), 168-176.

Kuh, G.D., Kinzie, J., Schuh, J.H., \& Whitt, E.J. (2005). Never let it rest; lessons about student success from high-performing colleges and universities. The Magazine of Higher Learning, 37(4) (Jul-Aug), 44-51.

Midwifery Council of New Zealand. (2007). Standards for approval of preregistation midwifery education programmes and accreditation of tertiary education organisations. Wellington, NZ: Midwifery Council of New Zealand.

Midwifery Council of New Zealand. (2010). Midwifery workforce report 2009. Wellington, NZ: Midwifery Council of New Zealand.

Ministry of Education. (2010). Tertiary Education Strategy 2010-2015. Wellington, NZ: Ministry for Tertiary Education.

Ministry of Education. (2002). Highways and pathways; exploring New Zealand's e-learning opportunities. Wellington, NZ: E-Learning Advisory Group.

Normand, C., \& Littlejohn, A. (2006). Flexible Delivery: a model for analysis and implimentation of flexible programme delivery. Mansfield: All Enhancement Themes Publications.

O’Neill, K., Singh, G., \& O’Donoghue, J. (2004). Implementing e-learning programmes for higher education: A review of the literature. Journal of Information Technology Education 3, 313-23.

Pairman, S. (2005). From autonomy and back again: educating midwives across a century. Part 1. New Zealand College of Midwives Journal, 33, 4-8. Retrieved from www.midwife.org.nz/pdf/resources/JNL\%2033\%20Oct\%2005.pdf

Pairman, S. (2006). From autonomy and back again: educating midwives across a century. Part 2. New Zealand College of Midwives Journal, 34, 11-15. Retrieved from www.midwife.org.nz/search?q=issue +34

Pairman, S., \& Donnellan-Fernandez, R. (2010). Professional frameworks for practice in Australia and New Zealand, In S. Pairman, S. Tracy, C. Thorogood, $\&$ J. Pincombe, (Eds.), Midwifery: preparation for practice, (2nd ed.), (pp. $227-$ 255). Sydney, Australia: Elsevier.

Ramage, T. R. (2002). The no significance difference phenomenon: a literature review. Illinois, USA. Parkland College. Retrieved from http://GI/Projects/ web/e-jist/site/docs/html2002/ramage.html

School of Nursing and Midwifery. (2009). Bachelor of midwifery curriculum accreditation document. Hamilton, NZ: Waikato Institute of Technology.

Stojanovic, J. (2010). Midwifery in New Zealand 1904-1971. Birth Spirit Midwifery Journal, (5), 53-60. Retrieved from www.birthspirit.co.nzl BirthspiritMidwiferyJournal/Issue5FreePDFs/MidwiferyInNZ.pdf

U.S. Department of Education. (2009). Evaluation of evidence-based practices in online learning: A meta-analysis and review of online learning studies. Office of planning, evaluation and planning development. Washington D.C., USA: Department of Education.

Winne, P. H. (2010). Improving measurements of self-regulated learning. Educational Psychologist, 45(4), 267-276.

\section{Accepted for publication May 2014}

Milne, T., Skinner, J., Baird, K. (2014). Survey results of first and second year New Zealand midwifery student's level of engagement in flexible delivery programme. NZCOM Journal, 50, 5-10 http://dx.doi.org/10.12784/nzcomjnl50.2014.1.5-10

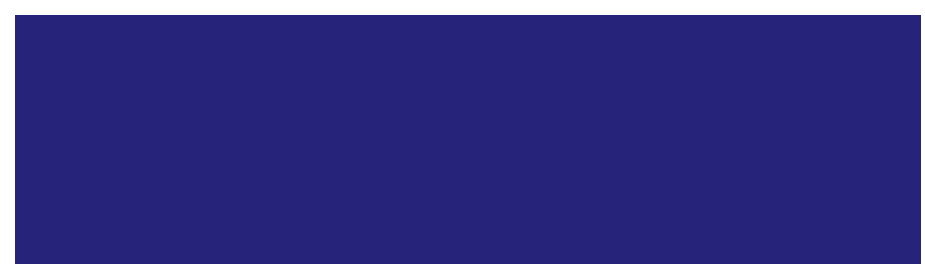

